\title{
Research
}

Jessica A Lee, Rachel Meacock, Evangelos Kontopantelis, James Matheson and Matthew Gittins

\section{Deprivation and primary care funding in Greater Manchester after devolution:}

\author{
a cross-sectional analysis
}

\begin{abstract}
Background

In April 2016 Greater Manchester gained control of its health and social care budget, a devolution that aimed to reduce health inequities both within Greater Manchester and between Greater Manchester and the rest of the country.
\end{abstract}

\section{Aim}

To describe the relationship between practice location deprivation and primary care funding and care quality measurements in the first year of Greater Manchester devolution (2016/2017).

\section{Design and setting}

Cross-sectional analysis of 472 general practices in Greater Manchester in England.

\section{Method}

Financial data for each general practice were linked to the area deprivation of the practice location, as measured by the 2015 Index of Multiple Deprivation. Practices were categorised into five quintiles relative to national deprivation. NHS Payments data and indicators of care quality were compared across social deprivation quintiles.

\section{Results}

Practices in areas of greater deprivation did not receive additional funding per registered patient. Practices in less deprived quintiles received higher National Enhanced Services payments from NHS England than practices in the most deprived quintile. A trend was observed towards funding to more deprived practices being supported by Local Enhanced Service payments from clinical commissioning groups, but these represent a small proportion of overall practice income. Practices in less deprived areas had better care quality measurements according to Quality and Outcomes Framework achievement and Care Quality Commission ratings.

\section{Conclusion}

Following devolution, primary care practices in Greater Manchester are still reliant on funding from national funding schemes, which poorly reflect its deprivation. The devolved administration's ability to address health inequities at the primary care level seems uncertain

\section{Keywords}

deprivation; devolution; financing; inequalities; primary care; quality of care.

\section{INTRODUCTION}

Individuals in areas of deprivation have more complex healthcare needs, earlier mortality, and greater multimorbidity than individuals who reside in affluent areas. ${ }^{1-7}$ While many socioeconomic determinants of health are independent of 'medical management', health care can nonetheless attenuate their effects through reducing the severity and progression of disease. $4,6,8$ Success in this arena depends on how effectively care is delivered according to need across the socioeconomic spectrum, yet the availability of safe, effective health care tends to vary inversely with need." The reasons for this are multifaceted and complex, but depend partly on health financing.

Greater Manchester is an area of marked socioeconomic deprivation. ${ }^{9}$ In 2010, the chance of dying early (before 75 years) in northern regions such as Manchester was $20 \%$ higher than in the south of England. ${ }^{10}$ Socioeconomic deprivation explains up to two-thirds of this marked mortality divide."

In response to these health inequities, and out of frustration at a centralised, London-focused political economy, ${ }^{12}$ a growing devolution movement is building in England. 13,14 Greater Manchester is at the forefront of this experiment, having taken control of its $€ 6$ billion yearly health and social care budget in April 2016, as well as a Transformation Fund of $€ 450$ million. $^{15}$

JA Lee, BSc (Hons), medical student, School of Medical Sciences; R Meacock, BA, MSc, $\mathrm{PhD}$, senior lecturer in health economics: E Kontopantelis, BSc, MSc, PhD, professor of data science and health services research, Division of Informatics, Imaging and Data Sciences; M Gittins, PhD, lecturer in biostatistics, Division of Population Health, Health Services Research and Primary Care, University of Manchester, Manchester. J Matheson, BA (Hons), MBBS, DMCC, GP, Hill Top Surgery, Hope Citadel Healthcare, Shared Health Foundation, Oldham.
The devolution, styled 'DevoManc', has two stated aims: to improve the health of the Greater Manchester population, and to reduce the existing health inequalities. ${ }^{13}$

In light of these ambitions, this study aimed to examine the relationship between funding allocations to primary care practices within Greater Manchester and area-level deprivation of practice location during the first year of the new Greater Manchester Health and Social Care Partnership. Given the role of primary care as the cornerstone of the healthcare system, if devolution of health and social care spending is to achieve its aim of reducing health inequalities, higher funding allocations would be expected in areas of greater deprivation.

Because of the importance of the quality of care provided, this study further aimed to describe the relationship between practice location deprivation and measures of primary care quality. Quality is examined as measured by the Quality and Outcomes Framework (QOF) and the Care Quality Commission (CQC).

\section{Primary care funding in England}

Across England, primary care funding is based on the fulfilment of contractual obligations for the provision of various agreed services. ${ }^{16}$ Core practice funding comes from the global sum (capitation) payment. This covers the provision of

\section{Address for correspondence}

Jessica A Lee, School of Medical Sciences, University of Manchester, Stopford Building. Oxford Road, Manchester M13 9PL, UK.

Email: leejessieannelagmail.com

Submitted: 16 March 2019; Editor's response: 18 April 2019; final acceptance: 10 May 2019. CBritish Journal of General Practice

This is the full-length article (published online 10 Sep 2019) of an abridged version published in print. Cite this version as: $\mathbf{B r} \mathbf{J}$ Gen Pract 2019; DOI: https://doi.org/10.3399/bjgp19X705545 


\section{How this fits in}

There has been no previous work looking at primary care funding or quality in the context of the devolution of the health and social care budget to Greater Manchester. Styled 'DevoManc', the devolution was promoted as a way to increase local autonomy and reduce the large health inequities in Greater Manchester. This work details how local control over primary care financing in Greater Manchester following devolution is limited, and primary care practices in highly deprived areas are not receiving additional funding, despite welldescribed greater need.

essential services (the everyday work of seeing patients during normal working hours), as well as some additional services. The global sum payment is calculated according to the Carr-Hill formula, which attempts to account for the needs of a practice's population and the cost of providing primary care services. ${ }^{17-19}$ Additional funding is received through Enhanced Service and QOF payments. ${ }^{20}$

Enhanced Service payments are for non-essential services and may be commissioned nationally (National Enhanced Service payments) by NHS England, or locally (Local Enhanced Service payments) by clinical commissioning groups (CCGs) to meet local health needs. ${ }^{2}$ Enhanced Service payments also include Direct Enhanced Service payments for vaccinations and minor procedures Further payments are made for premises, administration, physician seniority, and prescribing fees. Together these form the total NHS payments made to GP practices. Deductions for pensions and professional levies are excluded from these totals. ${ }^{20}$

The QOF is a pay-for-performance scheme where payments are provided to practices based on their performance against targets. Exception reporting, now re-termed 'Personalised Care Adjustments', permits practice staff to exclude certain patients from these pay-for-performance calculations without financial penalisation, for a variety of reasons including where care is deemed 'unsuitable' for the patient, or where the client chooses not to receive the prescribed care or does not respond to invitations. ${ }^{22-24}$

\section{METHOD}

\section{Data}

Publicly available financial and care quality data were accessed for all primary care practices active in Greater Manchester for the full 2016/2017 financial year $(n=472)$. Data for total NHS payments were downloaded from NHS Digital. ${ }^{25}$ Practice postcodes were matched to English Indices of Multiple Deprivation (IMD) data 2015. ${ }^{26}$ Practices were then ranked into deprivation quintiles according to their postcode, where 5 is the most deprived and 1 the least deprived quintile relative to national deprivation.

Quality of care ratings for practices inspected before the end of the 2016/2017 financial year were downloaded from the $C Q C,{ }^{27}$ verified using unique six-letter practice identifiers, and matched with collated financial and deprivation data. Any rating made after the end of the 2016/2017 financial year was only used where there was no previous rating. CQC data were available for only 436 (92\%) practices, with 28 practices $(6 \%)$ not inspected, and eight practices $(2 \%)$ with unavailable data.

\section{Analyses}

To allowforvarying list sizes across practices, the average payment per registered patient Itotal payments before deductions divided by number of registered patients ${ }^{20}$ and the average payment per weighted patient (total payments before deductions divided by the number of weighted patients, as calculated by the Carr-Hill formulal were examined. ${ }^{20}$ The various main sub-payments were also examined separately as they come from different sources: National Enhanced Service payments per registered patient, Local Enhanced Service payments per registered patient, and QOF payments per registered patient.

The relationship between the practice payment variables and deprivation was estimated using a multivariable linear regression model. Confounders were decided a priori, in accordance with factors previously described to affect financial need. ${ }^{19,28}$ All models controlled for practice contract type General Medical Services, Personal Medical Services, or Alternative Provider Medical Services). Practice location rurality was also controlled for in the analysis of National Enhanced Service, Local Enhanced Service, and QOF payments. Rurality was not included in the analysis of the average payment per registered patient or the average payment per weighted patient because it is already accounted for in the Carr-Hill formula, which determines the global sum payment.

Whether measures of primary care quality vary by practice location deprivation was also investigated. Linear 
regression models were used to quantify the association between deprivation and total QOF achievement or exception rates (clinical domain), controlling for list size, contract type, and practice location rurality. The four CQC ratings categories were dichotomised into "Inadequate and Requires Improvement' and 'Good and Outstanding'. To dichotomise quintiles equally, IMD decile categories were used and combined (1-5 and $6-10)$. Fisher's exact test was then used to examine the association between CQC rating and practice location deprivation. All analyses were undertaken in SPSS (version 23).

\section{RESULTS}

\section{Overview of practice characteristics}

The 472 practices active in Greater Manchester in 2016/2017 served 3010596 patients. When relative area-level deprivation was compared nationally, 52\% ( $n=245$ ) of practices in Greater Manchester were located in the most deprived quintile, and $73 \%(n=346)$ in the two most deprived quintiles (Figure 1).

Table 1 presents descriptive statistics for the outcomes of interest and confounders across the five social deprivation quintiles. The average list size was smallest for practices in the most deprived quintile at 5738, and increased as quintiles became less deprived, before decreasing again in quintile 1.

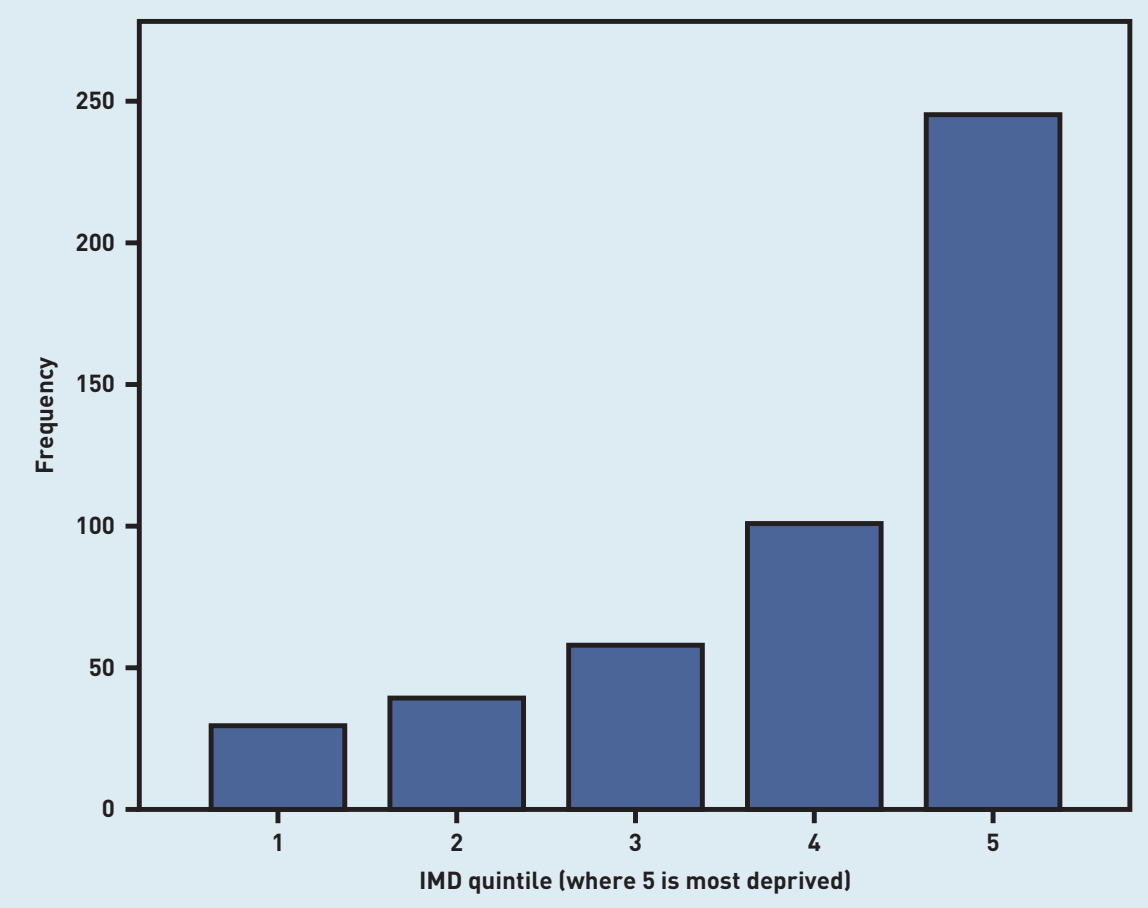

\section{Practice area deprivation and primary care funding}

The average practice in the most deprived quintile (quintile 5) received $£ 159$ per registered patient. This fell to $€ 142$ for practices in quintile 4 and $€ 136$ for practices in quintile 3 , before increasing slightly to £141 in quintile 2, and £142 in quintile 1 (the least deprived). Following weighting by the Carr-Hill formula, practices in both the most and least deprived quintiles received the same average payment per weighted patient of $€ 147$. This was higher than the average payment per weighted patient for practices in quintiles 4 (E136), 3 (E131), and 2 (£141) (Table 1). However, after controlling for contract type, there were no statistically significant differences in average payments per registered patient or per weighted patient by deprivation quintile in the first year of devolution (confidence intervals cross zerol (Table 2).

National Enhanced Service payments were small. The median practice payment was $\mathrm{E394}$ (the mean practice National Enhanced Service payment on a per patient basis was £0.14) (Table 1) and 25 practices received no National Enhanced Service funding at all. National Enhanced Service payments per registered patient were significantly higher for practices in deprivation quintiles 2,3 , and 4 , compared with practices in the most deprived quintile (Table 2). Practices in quintile 2 received the largest National Enhanced Service payments, £1000 more per practice than those in the most deprived quintile.

Local Enhanced Service payments provided more income, with the average practice receiving $£ 100182$ (the mean practice LES payment on a per patient basis was E16.76). A trend was observed towards decreasing Local Enhanced Service payments per registered patient as practice area deprivation decreased. However, confidence intervals (CI) are wide (Table 2).

There was variation in the QOF payments per patient received by practices (£2-157). with practices receiving an average of £12.14 per registered patient (Table 1). After controlling for practice rurality and contract type, a significant relationship was not detected between QOF payments per registered patient and practice area deprivation (Table 2).

\section{Practice area deprivation and primary care quality}

Mean total percentage QOF achievement in the clinical domain was high $(96.05 \%)$ (Table 1). A trend towards higher QOF 
Table 1. Descriptive statistics per practice of outcomes and primary confounders split by IMD social deprivation quintiles

\begin{tabular}{|c|c|c|c|c|c|c|c|}
\hline \multirow[b]{2}{*}{ Number of practices } & \multirow[b]{2}{*}{ Variable } & \multicolumn{5}{|c|}{ Deprivation quintile } & \multirow[b]{2}{*}{$\begin{array}{c}\text { Total or average } \\
\qquad n=472\end{array}$} \\
\hline & & $\begin{array}{c}5 \text { (most deprived) } \\
n=245\end{array}$ & $\begin{array}{c}4 \\
n=101\end{array}$ & $\begin{array}{c}3 \\
n=58\end{array}$ & $\begin{array}{c}2 \\
n=39\end{array}$ & $\begin{array}{c}1 \text { (least deprived) } \\
n=29\end{array}$ & \\
\hline \multirow[t]{2}{*}{ List size } & Mean (SD) & $5738(3141)$ & 6838 (4187) & 7155 (3983) & 7444 (4089) & 6839 (4258) & 6356 (3691) \\
\hline & Range & $1125-21712$ & $1577-29614$ & $1772-16760$ & $1892-16728$ & $1638-20320$ & $1125-29614$ \\
\hline Practice rurality & $\begin{array}{l}\text { Frequency } \\
\text { urban }(\%)\end{array}$ & $245(100)$ & 101 (100) & $58(100)$ & $35(90)$ & $29(100)$ & $468(99)$ \\
\hline \multirow{2}{*}{ Contract type } & GMS frequency (\%) & 185 (75.5) & 68 (67.3) & 50 (86.2) & $25(64.1)$ & $17(58.6)$ & 345 (73.1) \\
\hline & PMS frequency (\%) & 39 (15.9) & $29(28.7)$ & $8(13.8)$ & $11(28.2)$ & 11 (37.9) & $98(20.8)$ \\
\hline \multirow[t]{2}{*}{ Total payments, $€$} & Mean (SD) & 803867 (486 204) & 866973 (497 923) & 846883 (504 127) & 923717 (494 201) & 854000 (523 521) & 840056 (493 467) \\
\hline & Range & $116916-3747783$ & $203087-3291125$ & $230638-2496808$ & $273010-1887854$ & $201872-2385852$ & $116915-3747783$ \\
\hline \multirow{2}{*}{$\begin{array}{l}\text { Average payment per } \\
\text { registered patient, }^{\mathrm{a}} €\end{array}$} & Mean (SD) & 159 (95) & 142 (27) & $136(16)$ & 141 (30) & $142(65)$ & 150 (73) \\
\hline & Range & $103-1155$ & $89-247$ & $101-179$ & $107-272$ & $104-474$ & 89-1155 \\
\hline $\begin{array}{l}\text { Average payment per } \\
\text { weighted patient, }{ }^{\mathrm{b}} €\end{array}$ & Mean (SD) & 147 (74) & $136(26)$ & 131 (13) & 141 (30) & $147(64)$ & 142 (58) \\
\hline \multirow{2}{*}{$\begin{array}{l}\text { National Enhanced } \\
\text { Service payments per } \\
\text { registered patient, } €\end{array}$} & Mean (SD) & 0.09 (0.122) & $0.17(0.354)$ & $0.16(0.275)$ & $0.32(0.479)$ & 0.14 (0.183) & $0.14(0.26)$ \\
\hline & Range & $0-1$ & $0-3$ & $0-2$ & $0-2$ & $0-1$ & $0-3$ \\
\hline \multirow{2}{*}{$\begin{array}{l}\text { Local Enhanced Service } \\
\text { payments per } \\
\text { registered patient, } €\end{array}$} & Mean (SD) & 18.73 (37.35) & 17.49 (28.89) & $13.79(8.44)$ & $12.27(5.97)$ & $9.53(6.90)$ & $16.76(29.98)$ \\
\hline & Range & $1-503$ & $1-200$ & $2-34$ & $2-26$ & $0-25$ & $0-503$ \\
\hline \multirow{2}{*}{$\begin{array}{l}\text { QOF payments per } \\
\text { registered patient, } €\end{array}$} & Mean (SD) & $12.17(9.75)$ & $12.02(2.74)$ & 12.41 (2.58) & $12.25(1.99)$ & 11.69 (1.98) & 12.14 (7.23) \\
\hline & Range & 2-157 & $3-21$ & $4-18$ & $7-16$ & $7-16$ & 2-157 \\
\hline \multirow[t]{2}{*}{ QOF achievement, \%c } & Mean (SD) & 95.05 (6.64) & $97.29(3.19)$ & $96.43(6.37)$ & 97.54 (3.29) & 97.39 (3.18) & 96.05 (5.71) \\
\hline & Range & $52.95-100.00$ & 85.69-100.00 & 69.67-100.00 & $87.06-100.00$ & $89.28-100.00$ & $52.95-100.00$ \\
\hline \multirow{2}{*}{$\begin{array}{l}\text { Exceptioning rate } \\
\text { (clinical domain)c }\end{array}$} & Mean (SD) & 8.61 (3.99) & $9.07(3.74)$ & 7.68 (3.18) & $9.56(4.20)$ & 6.85 (2.89) & 8.56 (3.84) \\
\hline & Range & $0.00-21.36$ & $3.01-21.26$ & $3.05-17.24$ & $2.88-24.34$ & $2.49-13.27$ & $0.00-24.34$ \\
\hline \multicolumn{2}{|l|}{ Number of practices } & $n=220$ & $n=99$ & $n=54$ & $n=38$ & $n=25$ & $n=436$ \\
\hline \multirow{2}{*}{ CQC ratings } & $\begin{array}{l}\text { Requires } \\
\text { improvement (\%) }\end{array}$ & 5 (2.3) & $4(4.0)$ & $1(1.9)$ & $0(0)$ & $0(0)$ & $10(2.3)$ \\
\hline & Inadequate (\%) & 7 (3.2) & $0(0)$ & $0(0)$ & $0(0)$ & $0(0)$ & $7(1.6)$ \\
\hline
\end{tabular}

${ }^{a}$ Registered patients is the number of patients registered at each practice at the end of the financial year. ${ }^{b}$ Weighted patients is the number of patients per practice as calculated by the global sum formula to estimate patient workload. Average payments per patient describe the total payments figure (before deductions), divided by either the number of registered or weighted patients. 'Data from QOF dataset, not NHS payments dataset. APMS = Alternative Provider Medical Services. CQC = Care Quality Commission. GMS = General Medical Services. IMD = Index of Multiple Deprivation. PMS = Personal Medical Services. QOF = Quality and Outcomes Framework.

achievement was observed moving from the most to the least deprived quintile, with practices in quintiles 1,2 , and 4 achieving significantly higher performance than practices in the most deprived quintile (Table 3); however, for quintile 1 confidence intervals cross zero. Total exceptioning rate varied between $0 \%$ and $24.3 \%$ (mean $=8.56$ ), with three practices exceptioning 0 patients (Table 1). Practices in the least deprived IMD quintile exceptioned 1.7 percentage points fewer patients in the clinical domain than those in the most deprived quintile (IMD $5=-1.712 ; 95 \% \mathrm{Cl}=-3.15$ to -0.274$)$ (Table 3). However, IMD quintile 2 had the highest exceptioning rate and no clear relationship was observed between the rate of exception reporting and practice area deprivation (Table 3).

Of the 436 practices with $C Q C$ ratings, most (398 practices, 91.3\%) were rated 'Good'. Of the remaining $38(8.7 \%), 21$ practices (4.8\%) were classified as 'Outstanding', $10(2.3 \%)$ as 'Requires Improvement', and seven (1.6\%) as 'Inadequate'. All seven practices deemed 'Inadequate' were in the most deprived quintile, and nine of the 10 practices requiring improvement were in the two most deprived quintiles (Table 1). There was a significant difference 


\section{Table 2. Estimated regression associations between primary care payments and practice area deprivation quintile}

\begin{tabular}{|c|c|c|}
\hline Dependent variable & Unstandardised coefficient, B & $95 \% \mathrm{Cl}$ \\
\hline \multicolumn{3}{|c|}{ Average payments per registered patient } \\
\hline Quintile 4 & -7.073 & -22.517 to 8.371 \\
\hline Quintile 3 & -5.234 & -24.756 to 14.289 \\
\hline Quintile 2 & -14.234 & -32.379 to 3.912 \\
\hline (least deprived) Quintile 1 & -10.483 & -34.310 to 13.344 \\
\hline Contract type PMS & 5.871 & -8.088 to 19.829 \\
\hline Contract type APMS & 162.395 & 138.823 to 185.967 \\
\hline \multicolumn{3}{|c|}{ Average payments per weighted patient } \\
\hline Quintile 4 & -5.352 & -16.382 to 5.679 \\
\hline Quintile 3 & -3.105 & -16.691 to 10.481 \\
\hline Quintile 2 & -5.209 & -21.193 to 10.775 \\
\hline (least deprived) Quintile 1 & 5.499 & -12.808 to 23.807 \\
\hline Contract type PMS & 8.893 & -1.858 to 19.644 \\
\hline Contract type APMS & 140.780 & 122.777 to 158.784 \\
\hline \multicolumn{3}{|c|}{ NES payments per registered patient } \\
\hline Quintile 4 & 0.072 & 0.013 to 0.131 \\
\hline Quintile 3 & 0.069 & -0.003 to 0.142 \\
\hline Quintile 2 & 0.197 & 0.108 to 0.287 \\
\hline (least deprived) Quintile 1 & 0.032 & -0.066 to 0.130 \\
\hline Practice rurality & -0.264 & -0.526 to -0.002 \\
\hline Contract type PMS & 0.065 & 0.008 to 0.123 \\
\hline Contract type APMS & -0.026 & -0.123 to 0.070 \\
\hline \multicolumn{3}{|c|}{ LES payments per registered patient } \\
\hline Quintile 4 & -0.085 & -7.001 to 6.832 \\
\hline Quintile 3 & -2.856 & -11.375 to 5.663 \\
\hline Quintile 2 & -6.947 & -17.437 to 3.544 \\
\hline (least deprived) Quintile 1 & -7.895 & -19.375 to 3.584 \\
\hline Practice rurality & -7.143 & -37.774 to 23.489 \\
\hline Contract type PMS & -0.267 & -7.017 to 6.482 \\
\hline Contract type APMS & 24.402 & 13.110 to 35.694 \\
\hline \multicolumn{3}{|c|}{ QOF payments per registered patient } \\
\hline Quintile 4 & -0.026 & -1.724 to 1.673 \\
\hline Quintile 3 & 0.518 & -1.574 to 2.609 \\
\hline Quintile 2 & -0.161 & -2.737 to 2.415 \\
\hline (least deprived) Quintile 1 & -0.354 & -3.173 to 2.465 \\
\hline Practice rurality & -2.447 & -9.969 to 5.074 \\
\hline Contract type PMS & 0.187 & -1.470 to 1.845 \\
\hline Contract type APMS & 3.145 & 0.372 to 5.918 \\
\hline
\end{tabular}

APMS = Alternative Provider Medical Services. $C l=$ confidence interval. $L E S=$ Local Enhanced Service.

NES = National Enhanced Service. PMS = Personal Medical Services. QOF = Quality and Outcomes Framework. in dichotomised CQC rating (Outstanding/ Good versus Inadequate/Requires Improvement) across IMD strata (Fisher's exact 2 -sided test $P$-value $=0.03$.

\section{DISCUSSION}

\section{Summary}

Devolution of the health and social care budget for Greater Manchester aimed to reduce the existing health inequalities present in the region. In light of these ambitions, this study aimed to examine the relationship between primary care funding and practice area deprivation in the first year of devolved funding. No relationship was found between practices' area deprivation quintile and average payments per registered patient, despite well-described greater need among patients in these more deprived areas. ${ }^{2,5,6,19}$

Practices in less deprived quintiles actually received higher National Enhanced Service payments from NHS England than practices in the most deprived quintile. Although a trend was observed towards funding to more deprived practices being supported by Local Enhanced Service payments from CCGs, these represent a small proportion of overall practice income. Most practice funding still comes from the global sum (capitation payment), with on average $11 \%$ of the average payment per registered patient in Greater Manchester coming from Local Enhanced Service payments, 8\% from QOF payments, and $<1 \%$ from National Enhanced Service payments. There was also evidence that practices in less deprived areas were of better quality according to QOF achievement and $C Q C$ ratings than practices in the most deprived quintile.

\section{Strengths and limitations}

This study analysed payments data for all 472 practices active in the Greater Manchester region during 2016/2017, covering more than 3 million patients across all 10 Greater Manchester CCGs. DevoManc aims to reduce health inequalities through local control of the health and social care budget. This study therefore examined how one key component of health and social care funding, that flowing to primary care, was allocated in relation to deprivation, a key determinant of healthcare need.

This study is based on publicly reported data, and so it is limited in terms of the information it was possible to include on known confounders, such as practice populations' ethnicity, age, sex, comorbidity, language barriers, and turnover., ${ }^{4,28-31}$ In addition, it was only possible to analyse deprivation by practice location, not patient address. Although previous work has shown practice deprivation to be a good indicator of patient deprivation, ${ }^{4}$ there is potential for misclassification.

\section{Comparison with existing literature}

A relationship between practice deprivation and average payment per weighted patient was not observed. This accords with previous work, which has raised concerns that national funding formulae, such as the Carr-Hill formula and the QOF, fail to sufficiently take into account the 


\section{Table 3. Estimated regression associations between QOF ratings and} practice area deprivation quintile

\begin{tabular}{lcc} 
Dependent variable & Unstandardised coefficient, B & $\mathbf{9 5 \%} \mathbf{~ C l}$ \\
\hline Total percentage QOF achievement (clinical domain) & & \\
Quintile 4 & 1.990 & 0.678 to 3.303 \\
Quintile 3 & 1.167 & -0.450 to 2.785 \\
Quintile 2 & 2.155 & 0.164 to 4.145 \\
(least deprived) Quintile 1 & 2.052 & -0.118 to 4.222 \\
List size per 100 patients & 0.025 & 0.011 to 0.040 \\
Practice rurality & 1.325 & -4.464 to 7.115 \\
Contract type PMS & 0.409 & -0.869 to 1.687 \\
Contract type APMS & 1.693 & -0.467 to 3.852 \\
\hline Exception rate (clinical domain) & & \\
Quintile 4 & 0.430 & -0.439 to 1.300 \\
Quintile 3 & -1.003 & -2.075 to 0.068 \\
Quintile 2 & 0.689 & -0.630 to 2.008 \\
(least deprived) Quintile 1 & -1.712 & -3.150 to -0.274 \\
List size per 100 patients & 0.022 & 0.012 to 0.031 \\
Practice rurality & 0.044 & -3.792 to 3.880 \\
Contract type PMS & -0.604 & -1.450 to 0.243 \\
Contract type APMS & 2.912 & 1.481 to 4.343 \\
\hline
\end{tabular}

$\mathrm{Cl}=$ confidence interval. QOF $=$ Quality and Outcomes Framework . and political appeal as an opportunity to make in-house decisions about health and social care, and as a chance to address profound health inequities. ${ }^{12,13}$ However, as this work shows, these inequities continue to persist in primary care funding allocation.

An explanation for this is that, behind the rhetoric, DevoManc has no statutory basis, and is not an exercise in local control or autonomy over policy, but rather over its implementation. ${ }^{12}$ It describes an agreement for administrative delegation between the Department of Health and Social Care, NHS Improvement/England, and local authorities and care organisations in Greater Manchester. ${ }^{12}$ For primary care, this has meant creating governance arrangements to integrate planning, delivery, and governance across already existing CCGs. ${ }^{13}$ Certainly, this allows greater focus on relationship building and reorganisation. However, Greater Manchester remains governed by national policy. National funding schemes, such as the QOF and the global sum payment, still form the basis of general practice income in Greater Manchester despite failing to account for the additional unmet health needs of deprived populations. The $€ 450$ million Transformation Fund, established to help :... make all the changes [required] to dramatically improve health and social care in Manchester ...,33 appears to have had minimal contribution to improving these funding imbalances. Thus, claims about DevoManc producing much needed improvements in health inequities, particularly in light of the central government-led austerity firmly embedded in the devolution process, should be treated with caution. ${ }^{32}$ By 2020, Greater Manchester is predicted to have a shortfall in funding of several billion pounds a year that, even with integration and improved efficiency of services, ${ }^{34}$ will likely curtail capacity for local responsiveness.

Nevertheless, some success has been had by the new organisational structure at championing regional priorities within central government, with Greater Manchester successfully competing to gain access to limited national capital for several tailored health programmes. ${ }^{32}$ However, as this study demonstrates, the ability of devolution to address the issues (the inequalities), on which it was promoted, remains to be questioned. Further translational investigation is clearly indicated to assess how Greater Manchester may tackle deprivation and health inequities, within its limited remit, and to investigate alternative financing structures. 


\section{REFERENCES}

1. McLean G, Guthrie B, Mercer SW, Watt GC. General practice funding underpins the persistence of the inverse care law: cross-sectional study in Scotland. Br J Gen Pract 2015; DOI: https://doi.org/10.3399/bjgp15X687829.

2. Barnett K, Mercer SW, Norbury M, et al. Epidemiology of multimorbidity and implications for health care, research, and medical education: a crosssectional study. Lancet 2012; 380(9836): 37-43.

3. Carstairs V, Morris R. Deprivation and mortality: an alternative to social class? Community Med 1989; 11(3): 210-219.

4. Kontopantelis E, Springate DA, Ashcroft DM, et al. Associations between exemption and survival outcomes in the UK's primary care pay-forperformance programme: a retrospective cohort study. BMJ Qual Saf2016. 25(9): 657-670.

5. Asaria M, Doran T, Cookson R. The costs of inequality: whole-population modelling study of lifetime inpatient hospital costs in the English Nationa Health Service by level of neighbourhood deprivation. J Epidemiol Community Health 2016; 70(10): 990-996.

6. Marmot M. Fair society, healthy lives: the Marmot review. London: Marmot Review, 2010.

7. Hart JT. The inverse care law. Lancet 1971; 1(7696): 405-412.

8. Barr B, Bambra C, Whitehead M. The impact of NHS resource allocation policy on health inequalities in England 2001-11: longitudinal ecological study. BMJ 2014; 348: g3231.

9. Kontopantelis E, Mamas MA, van Marwijk H, et al. Geographical epidemiology of health and overall deprivation in England, its changes and persistence from 2004 to 2015: a longitudinal spatial population study. J Epidemiol Community Health 2018; 72(2): 140-147.

10. Buchan IE, Kontopantelis E, Sperrin M, et al. North-South disparities in English mortality 1965-2015: longitudinal population study. J Epidemiol Community Health 2017; 71(9): 928-936.

11. Kontopantelis E, Buchan I, Webb RT, et al. Disparities in mortality among 25-44-year-olds in England: a longitudinal, population-based study. Lancet Public Health 2018; 3(12): e567-e575.

12. Walshe K, Lorne C, Coleman A, et al. Devolving health and social care: learning from Greater Manchester. Manchester: University of Manchester, 2018.

13. Walshe K, Coleman A, McDonald R, et al. Health and social care devolution: the Greater Manchester experiment. BMJ 2016; 352: 11495.

14. Local Government Association. English devolution: local solutions for a successful nation. London: LGA, 2015.

15. Greater Manchester Combined Authority. Devolution. 2018. https://www. greatermanchester-ca.gov.uk/who-we-are/devolution laccessed 6 Aug 2019).

16. Burch P. Funding in primary care. InnovAiT 2018; 12(2): 100-104

17. British Medical Association. Focus on the global sum allocation formula (CarrHill formula). London: BMA, 2015.

18. Elliott B, Sutton M, Gravelle H, et al. Adjusting the General Medical Services allocation formula to reflect recruitment and retention difficulties. Aberdeen: University of Aberdeen, 2006.
19. Kontopantelis E, Mamas MA, van Marwijk H, et al. Chronic morbidity, deprivation and primary medical care spending in England in 2015-16: a crosssectional spatial analysis. BMC Med 2018; 16(1): 19.

20. NHS Digital. NHS payments to general practice, England, 2016/17. 2017. https://files.digital.nhs.uk/publication/4/t/nhspaymentsgp-16-17-rep.pdf laccessed 6 Aug 2019).

21. British Medical Association. GP contract Enhanced Services. 2018. https:// www.bma.org.uk/advice/employment/contracts/general-practice-funding/ gp-contract-2015-2016-england/gp-contract-enhanced-services laccessed 6 Aug 2019).

22. NHS Employers, British Medical Association, NHS England. 2016/17 General Medical Services (GMS) contract Quality and Outcomes Framework (QOF). London: NHS Employers, 2016.

23. Doran T, Kontopantelis E, Fullwood C, et al. Exempting dissenting patients from pay for performance schemes: retrospective analysis of exception reporting in the UK Quality and Outcomes Framework. BMJ 2012; 344: e2405.

24. British Medical Association. The Quality and Outcomes Framework (QOF). 2019. https://www.bma.org.uk/-/media/files/pdfs/collective voice/committees/gpc/gpc england/contract agreement qof guidance-jan2019.pdf?la=en laccessed 21 Aug 2019).

25. NHS Digital. Home - NHS Digital. 2019. https://digital.nhs.uk/ laccessed 21 Aug 2019).

26. Ministry of Housing, Communities and Local Government. English Indices of Deprivation 2015. 2015. https://uww.gov.uk/government/statistics/englishindices-of-deprivation-2015 (accessed 6 Aug 2019).

27. Care Quality Commission. What we do. 2019. http://www.cqc.org.uk/what-wedo (accessed 6 Aug 2019).

28. Wright J, Martin D, Cockings S, Polack C. Overall quality of outcomes framework scores lower in practices in deprived areas. Br J Gen Pract 2006; 56(525): 277-279

29. Baird B, Charles A, Honeyman M, et al. Understanding pressures in general practice. London: King's Fund, 2016

30. NHS England, Primary Care Commissioning. Guidance note: GP practices serving atypical populations. Leeds: NHS England, 2016.

31. Health and Social Care Information Centre. QOF management guide. Leeds: HSCIC, 2009.

32. Lorne C, McDonald R, Walshe K, Coleman A. Regional assemblage and the spatial reorganisation of health and care: the case of devolution in Greater Manchester, England. Sociol Health Illn 2019; DOI: 10.1111/1467-9566.12867.

33. Greater Manchester Health and Social Care Partnership. What is the Transformation Fund?2016. http://uww.gmhsc.org.uk/wp-content/ uploads/2018/04/Transformation-Funding-FAQ.pdf laccessed 6 Aug 2019).

34. Greater Manchester Combined Authority. Taking charge of our health and social care in Greater Manchester: the plan. 2015. http://www.gmhsc.org.uk/ wp-content/uploads/2018/04/GM-Strategic-Plan-Final.pdf laccessed 6 Aug 2019). 